\title{
CONTRIBUIÇÕES DA DISCIPLINA DIDÁTICA PARA A FORMAÇÃO EM SAÚDE COLETIVA: RELATO DE EXPERIÊNCIA
}

\section{CONTRIBUTIONS OF THE DIDACTICS SUBJECT FOR THE TRAINING IN COLLECTIVE HEALTH: EXPERIENCE REPORT}

\section{CONTRIBUCIONES DE LA DISCIPLINA DIDÁCTICA PARA LA FORMACIÓN EN SALUD COLECTIVA: INFORME DE EXPERIENCIA}

\author{
Hayla Nunes da Conceição ${ }^{1}$ \\ Mariana Rodrigues da Rocha ${ }^{2}$ \\ Haylla Simone Almeida Pacheco ${ }^{3}$ \\ Sara Ferreira Coelho ${ }^{4}$ \\ Hilda Maria Martins Bandeira 5 \\ Maria do Socorro Leal Lopes ${ }^{6}$
}

Como citar este artigo: Conceição HN, Rocha MR, Pacheco HSA, Coelho SF, Bandeira HMM, Lopes MSL. Contribuições da disciplina Didática para a formação em saúde coletiva: relato de experiência. Rev baiana enferm. 2021;35:e37765.

Objetivo: descrever as contribuições da disciplina Didática para a formação em saúde coletiva. Método: trata-se de um relato de experiência, do tipo descritivo, detalhado, no contexto da disciplina Didática, ministrada no segundo semestre de 2019, no Programa de Pós-Graduação em Saúde e Comunidade da Universidade Federal do Piauí. Para discussão, o relato possui duas partes: vivência e experiência com a disciplina Didática na pós-graduação e desafios da Didática para os profissionais da saúde. Resultados: a disciplina Didática permitiu a compreensão do processo pedagógico como multidimensional, proporcionando a ruptura da concepção da disciplina apenas como um conjunto de métodos instrumentais para a prática docente. Conclusão: a disciplina possibilitou o entendimento do complexo campo da Didática como um desafio para os profissionais de saúde coletiva e constituiu-se em componente importante na matriz curricular de formação desses profissionais.

Descritores: Educação Superior. Saúde Pública. Docência. Educação em Saúde. Didática.

Objective: to describe the contributions of Didactics discipline to the formation in public health. Method: this is an experience report, descriptive, detailed, in the context of didactics, taught in the second semester of 2019, in the Graduate Program in Health and Community of the Federal University of Piaui. For discussion, the report has two

\footnotetext{
Enfermeira. Especialista em Saúde Pública, Saúde da Família e Docência no Ensino Superior. Universidade Federal do Piauí. Teresina, Piauí, Brasil. haylanunes_cx@hotmail.com. http://orcid.org/0000-000 I-6035-8280.

Enfermeira. Especialista em Saúde Pública com Habilitação em Docência no Ensino Superior. Universidade Federal do Piauí. Teresina, Piauí, Brasil. http://orcid. org/0000-0002-4745-9690.

Enfermeira. Especialista em Auditoria em Enfermagem. Universidade Federal do Piauí. Teresina, Piauí, Brasil. http://orcid.org/0000-0002-I363-936X.

Fisioterapeuta. Especialista em Saúde da Família e Fisioterapia Neurológica. Universidade Federal do Piauí. Teresina, Piauí, Brasil. http://orcid.org/0000-0002-23।53902.

5 Pedagoga. Doutora em Educação. Professora Adjunta da Universidade Federal do Piauí. Teresina, Piauí, Brasil. http://orcid.org/0000-000 I-6439-0632.

6 Licenciada Plena em Pedagogia. Doutora em Educação. Professora Assistente da Universidade Federal do Piauí. Teresina, Piauí, Brasil. http://orcid.org/0000-000 I7950-1235.
} 
parts: experience and experience with the didactics discipline in graduate studies and didactic challenges for health professionals. Results: the didactics subject allowed the understanding of the pedagogical process as multidimensional, providing the rupture of the conception of the discipline only as a set of instrumental methods for teaching practice. Conclusion: the discipline enabled the understanding of the complex field of Didactics as a challenge for public health professionals and constituted an important component in the curricular matrix of training of these professionals.

\section{Descriptors: Higher Education. Public Health. Teaching. Health Education. Teaching.}

Objetivo: describir las contribuciones de la disciplina didáctica a la formación en salud pública. Método: se trata de un informe de experiencia, descriptivo, detallado, en el contexto de la didáctica, impartido en el segundo semestre de 2019, en el Programa de Posgrado en Salud y Comunidad de la Universidad Federal de Piauí. Para la discusión, el informe consta de dos partes: experiencia y experiencia con la disciplina didáctica en estudios de posgrado y retos didácticos para los profesionales de la salud. Resultados: la disciplina didáctica permitió la comprensión del proceso pedagógico como multidimensional, proporcionando la ruptura de la concepción de la disciplina sólo como un conjunto de métodos instrumentales para la práctica docente. Conclusión: la disciplina permitió la comprensión del complejo campo de la Didáctica como un reto para los profesionales de la salud pública y constituyó un componente importante en la matriz curricular de formación de estos profesionales.

Descriptores: Educación Superior. Salud Pública. Enseñanza. Educación para la Salud. Enseñanza.

\section{Introdução}

O conhecimento tornou-se um recurso importante na atual sociedade globalizada, uma vez que tudo está em constante desenvolvimento. Presume-se que os trabalhadores da saúde sejam aptos a avaliar cenários complexos, além de capazes para decidir agilmente qual estratégia deve ser utilizada, para ajustar, de maneira crítica, as ações a serem realizadas e os resultados esperados ${ }^{(1)}$.

Todo processo de formação docente deve incluir componentes curriculares que abordem sistematicamente o que deve ser feito na prática educativa pedagógica ${ }^{(2)}$. Dentre esses componentes, a Didática desempenha papel relevante, ao entender a docência como prática social determinada histórica e socialmente como atividade mediadora entre o fundamento educacional e a atividade educativa ${ }^{(3)}$.

O profissional docente está em constante processo de formação, pois, ao transformar outros seres, ao auxiliá-los na construção de conhecimento, é também transformado nesse processo ${ }^{(4)}$. Dessa forma, há uma parceria de modo ativo no processo de aquisição, transmissão e construção de conhecimento, em que docente e discente aprendem e desenvolvem-se mutuamente ${ }^{(5)}$.

Quando se associa educação e saúde é importante entender que a saúde envolve as condições necessárias de vida, tais como: "[...] condições de alimentação, habitação, educação, renda, meio ambiente, trabalho, transporte, emprego, lazer, liberdade, acesso e posse da terra e acesso a serviços de saúde."(6:4) . Deseja-se pensar educação em saúde como ferramenta de coleta e destinação de recursos para intervir e transformar as condições de vida da população, objetivando o alcance de uma saúde coletiva de qualidade ${ }^{(7)}$.

Dessa forma, o propósito da saúde coletiva, elaborado em aspectos orgânicos, políticos e comunitários, compreende o levantamento de determinantes da produção social em saúde, da doença e do cuidado, assumindo, portanto, um caráter interdisciplinar que sugere uma integração de distintos conhecimentos oriundos de diversas formações profissionais ${ }^{(8)}$.

Destaca-se que educar na saúde é comunicar um conhecimento adquirido na área para uma pessoa ou população, sem desconsiderar a subjetividade de cada ser, o conhecimento prévio e o contexto sociocultural em que estão inseridos, contribuindo, assim, para a construção do conhecimento $^{(7)}$. Então, pensar em práticas na saúde coletiva exige articulá-las com outros saberes e com um dado contexto.

Atualmente, o modelo de formação dos profissionais da saúde coletiva vem permitindo 
apenas a reprodução acrítica e alienada dos processos de trabalho na saúde, especialmente quando se fundamenta em processos pedagógicos que pouco propiciam a reflexão e estão baseados em referenciais biologicistas. Muitas vezes, esses processos estão calcados em concepções de aprendizagem que priorizam o conteúdo a ser absorvido e reproduzido sem integração com as práticas profissionais, e ainda ocorrem em ambientes autoritários, em que a relação professor/estudante reproduz relações de submissão e dominação ${ }^{(8)}$.

Assim, reconhecendo a necessidade de melhorar a preparação pedagógica docente para os profissionais da saúde coletiva, os programas de pós-graduação stricto sensu das instituições de ensino superior têm incluído novos componentes curriculares nos planos de curso como, por exemplo, a disciplina Didática.

O presente relato de experiência objetiva descrever as contribuições da disciplina Didática para a formação em saúde coletiva.

\section{Método}

Trata-se de um relato de experiência do tipo descritivo e detalhado no contexto da disciplina Didática, ministrada no segundo semestre de 2019, para uma turma multiprofissional do Programa de Pós-Graduação em Saúde e Comunidade, no Centro de Ciências da Saúde da Universidade Federal do Piauí (PPGSC/UFPI), composta por 17 alunos: seis enfermeiros, três nutricionistas, duas psicólogas, dois fisioterapeutas, uma assistente social e uma dentista. O PPGSC disponibiliza duas linhas de pesquisa: Análise de Situação de Saúde e Saúde na Escola.

A disciplina tem como ementa a discussão da necessidade da Didática na área de saúde coletiva, o planejamento de ensino e a organização da aula no paradigma emergente. Duas professoras pedagogas ministraram a disciplina em uma sala de aula do Centro de Ciências de Saúde (CCS/UFPI), às quintas-feiras, no turno da manhã, durante quatro horas/aula, totalizando 45 horas de estudo.
Os tópicos da disciplina foram divididos em três unidades nas quais foram tratados os seguintes temas: na primeira, os fundamentos epistemológicos da Didática, as abordagens e tendências educacionais; na segunda, o planejamento didático e a organização do trabalho pedagógico; e na terceira, discussão sobre a aula como manifestação pedagógica.

O procedimento adotado para facilitar o processo de ensino-aprendizagem na disciplina Didática foi a aula expositiva e dialogada com o uso de metodologias inovadoras. Priorizou-se a realização de atividades em grupo e individuais, incentivando a leitura, a produção de sínteses e o desenvolvimento de plano de aula para apresentações e discussões subsequentes em sala de aula.

A disciplina Didática estimulou o pensamento crítico dos alunos sobre sua definição e objeto de estudo. Instigou-os a compreender a Didática para além do "como fazer", dos métodos de uma disciplina, percebendo-a como uma síntese da totalidade dos aspectos sociais, educativos, técnicos e políticos nos quais foram produzidos.

\section{Resultados e Discussão}

Como não foi possível descrever todos os momentos da disciplina, o relato é apresentado neste artigo de forma sintética dividido em duas partes: vivência e experiência com a disciplina Didática na pós-graduação e desafios da Didática para os profissionais da saúde coletiva.

\section{Vivência e Experiência com a Disciplina Didática na Pós-Graduação}

A disciplina teve início em agosto de 2019. As aulas foram construídas em colaboração entre discentes e professoras. Estas foram mediadoras críticas das técnicas e dos procedimentos utilizados para a construção do conhecimento. A estratégia de ensino usada pelas mediadoras para proporcionar um processo de ensino-aprendizagem efetivo já apresentava indícios da diversidade de métodos que podem ser utilizados para permitir a produção do conhecimento. 
Durante a disciplina, os discentes foram apresentados a textos como: "Fundamentos de Didática" de Alessandro de Melo e Sandra Terezinha Urbanetz $^{(3)}$, que apresenta uma introdução sobre o conceito de Didática, considerando a constituição histórica e social dessa área de conhecimento vinculada à educação e à pedagogia; "O Paradigma Emergente e a Prática Pedagógica" de Marilda Aparecida Behrens ${ }^{(9)}$, que apresenta movimentos e paradigmas das práticas pedagógicas; "A Revisão da Didática", capítulo do livro de Vera Maria Candau ${ }^{(2)}$ intitulado "Rumo a Nova Didática" e "A Didática na Formação de Educadores - da Exaltação à Negação: a Busca da Relevância"(10) do livro da mesma autora com o título "A Didática em Questão", que apresenta a importância e a necessidade da construção e consolidação da didática fundamental e a superação da didática instrumental; e o capítulo VII do livro "Desafios para a Docência Universitária na Contemporaneidade" de Marcos T. Masetto ${ }^{(11)}$, intitulado "Planejamento da Disciplina e da Aula como Espaço e Tempo de Aprendizagem e de Formação Profissional", que discute a importância de planejar a disciplina e as aulas para o estímulo ao desenvolvimento de condições oportunas para o processo de ensino-aprendizagem. Esses textos serviram de base para proporcionar o ensino-aprendizado durante a disciplina.

Para a discussão desses textos, utilizaram-se metodologias ativas. Estas são usadas por professores em diversas áreas de formação e consistem em formas de desenvolver um processo de aprendizagem e de ensino, buscando conduzir a formação crítica e autônoma dos profissionais, estimulando a curiosidade e considerando as escolhas de cada indivíduo e da coletividade, mediante a prática e os contextos sociais em que os discentes estão inseridos ${ }^{(12)}$.

A discussão sobre fundamentos da didática, que teve como referência principal o capítulo do livro de Vera Maria Candau ${ }^{(2)}$, foi realizada com o apoio de mapas conceituais construídos e expostos pelos discentes, seguido da reflexão e discussão do texto. Tal atividade, realizada com a interação e participação de todos, além de organizar as principais ideias do texto, proporcionou a aprendizagem do assunto.

Com a leitura e discussão do livro foi possível entender que a didática está além da sala de aula, é mais que métodos utilizados para a realização de uma aula. A didática é uma atividade mediadora entre a pedagogia e a prática educativa. Tal atividade não pode ser pensada sem considerar a prática social ${ }^{(2)}$. Esse entendimento tornou possível fazer uma associação direta entre a didática e a prática profissional dos discentes nos ambientes de saúde e educação, pois percebeu-se que o uso da didática deve estar em todas as ações de educação. Mesmo que o local da prática educativa seja um hospital, uma clínica, uma praça, um domicílio, a didática torna-se necessária para mediar essa relação pedagógica na atuação dos profissionais de saúde, notadamente na articulação de "para quem fazer", "para que fazer" e "por que fazer", isto é, considerar a prática social dos indivíduos envolvidos, para possibilitar o ensino-aprendizagem e a transformação social.

De modo geral, qualquer pessoa está implicada com ações de educação e de saúde, mesmo sem perceber. Ocorre que os profissionais de saúde realizam constantemente ações de educação, inclusive a prática educativa é estabelecida como um cuidado em saúde. Dessa forma, é importante que esses profissionais compreendam a importância das práticas educativas com dimensão pedagógica, com intencionalidade consciente do planejamento das ações e do processo de operacionalização dessas práticas. Além disso, é igualmente relevante que considerem a integralidade dos participantes e do meio em que vivem $^{(13)}$.

No decorrer das atividades da disciplina Didática, observou-se a relação entre o planejado e o realizado, já que as professoras ministrantes foram considerando e fazendo ajustes para atender as necessidades que se manifestavam. Ainda fazendo uso de metodologias ativas, as professoras da disciplina dividiram a turma em quatro grupos para discussão do texto sobre paradigmas da prática pedagógica. Cada grupo ficou responsável pela construção de 
um material para sintetizar o texto base. Assim, foram construídos um sumário, um glossário, uma estória em quadrinhos e uma manchete de jornal.

$\mathrm{Na}$ aula seguinte, foi proposta a rotação por estação ${ }^{(14)}$, que consiste na separação dos alunos em grupos que apresentam atividades diferentes. Para essa aula, os grupos foram organizados de acordo com o material produzido. Dois membros de cada grupo ficavam na sua estação, para explicar como haviam construído o material; os outros dois entravam em contato com o material e os métodos de construção nas demais estações. Em seguida havia a troca dos membros que ficavam na estação, para que todos conhecessem o que havia sido produzido por todos os grupos. Esse momento foi bastante enriquecedor, pois possibilitou o compartilhamento dos conhecimentos adquiridos, exploração de detalhes não observados, bem como incentivou a síntese, a crítica e a produção de novos conhecimentos.

Os paradigmas da prática pedagógica foram divididos em conservadores e inovadores ${ }^{(9)}$. O paradigma conservador é representado pelas abordagens tradicional, escolanovista e tecnicista, que focam principalmente na reprodução do conhecimento, na repetição e nas visões mecanicistas do processo de ensino e aprendizagem. O paradigma inovador é representado pelas abordagens sistêmica, progressista e ensino com pesquisa, que buscam a superação das abordagens conservadoras, visando a produção do conhecimento por meio do envolvimento do aluno no processo educativo.

O detalhamento desses paradigmas foi essencial para que os discentes entendessem que a formação profissional esteve pautada no ensino conservador, em que o professor é o "detentor do saber" e os alunos, meros espectadores que deveriam ouvir sem nenhum questionamento. Os discentes perceberam ainda que, infelizmente, muitas vezes, são reprodutores de tais paradigmas em sua prática profissional. O conhecimento de novas abordagens possibilitou a percepção de que se pode pensar e fazer educação valorizando a parceria entre aluno e professor, enfatizando a problematização do contexto social e produzindo novos conhecimentos e a transformação da prática social.

Portanto, torna-se essencial o uso das metodologias ativas de ensino-aprendizagem no processo de educação em saúde, quando se busca maior interação teórico-prática que possa favorecer a formação de profissionais críticos, reflexivos, participantes e comprometidos na construção do conhecimento e do aprendizado, trabalhando de forma multiprofissional e levando em consideração as necessidades do sistema de saúde e a realidade da prática social ${ }^{(15)}$.

Após o entendimento da didática e de seus fundamentos nos paradigmas educacionais, discutiu-se, com base nas leituras dos textos, sobre o planejamento didático e a importância do planejar por parte dos professores, evidenciando que esse planejamento deve partir da reflexão sobre "para que, o que e como ensinar". O planejamento docente é fundamental, por ser um processo reflexivo que possibilita a programação das ações educativas, para que o processo de ensino-aprendizagem aconteça de forma efetiva e eficaz. Permite ainda a vinculação das atividades pedagógicas com problemáticas do contexto social ${ }^{(16)}$.

Assim, no processo de planejamento do ensino, devem ser respeitadas as diferenças dos seus participantes, por meio do uso de métodos que potencializem o pensamento crítico e reflexivo dos alunos, atentando-se também para a formação profissional, tendo em vista as particularidades sociais e políticas do meio em que estão inseridos ${ }^{(17)}$. Para que isso aconteça, são necessários o entendimento e o uso dos componentes - objetivos, conteúdos, metodologia, recursos didáticos, avaliação e referências - estruturantes para o planejamento em educação. Tais componentes são indispensáveis no uso do processo de ensino-aprendizagem sistematizado e na formação profissional.

Visando melhor entendimento desses componentes estruturantes que devem ser abordados em uma disciplina e/ou aula, as mediadoras da disciplina solicitaram a cada grupo que levasse o plano de ensino de uma disciplina para ser analisado por elas em sala de aula. 
Nesse momento, identificou-se a forma de organização, os componentes apresentados e as informações ausentes e inadequadas. O plano de ensino consiste em um documento elaborado pelo docente, em que é organizada sua proposta de trabalho em uma disciplina. O contato com o plano de ensino é essencial para a formação do docente e também para os profissionais de saúde, já que propiciam a sistematização das atividades com dimensão pedagógica ${ }^{(18-19)}$.

$\mathrm{Na}$ apresentação de cada plano de ensino, foram discutidas estratégias para o aprimoramento do instrumento e principais diferenças entre plano de ensino e plano de aula. Assim, ementa e objetivos gerais devem constar apenas no plano de ensino de uma disciplina; já os objetivos específicos devem ser apresentados apenas no plano de aula.

$\mathrm{Na}$ sequência do estudo sobre o planejamento e seu uso no ensino superior, foi proposto que os alunos planejassem e apresentassem uma aula sobre uma temática escolhida, dentro da sua área de atuação. Para a aula, seriam utilizados todos os conhecimentos adquiridos na disciplina Didática, desde a abordagem a ser utilizada em sala de aula, apoiada nos paradigmas das práticas pedagógicas, até os meios e métodos de planejamento do plano de aula e da aula propriamente dita. A vivência dessas aulas ministradas permitiu a simulação das provas de didática, comumente utilizadas para a seleção de professores, pois parte dos mestrandos evidenciaram essa motivação para atividade de docência. Para além do apresentado, possibilitou a aquisição de conhecimentos sobre as diversas áreas da saúde, uma vez que a turma era composta por profissionais de diferentes áreas da saúde.

\section{Desafios da Didática para os Profissionais de Saúde Coletiva}

Os principais desafios da Didática para os profissionais de saúde coletiva estão relacionados à ausência de conhecimentos pedagógicos ou à compreensão equivocada sobre $\mathrm{O}$ que é a didática e qual é o papel do professor e dos profissionais de saúde no processo de ensino-aprendizagem.

O principal desafio para a Didática, observado ainda nas primeiras aulas das disciplinas, foi a concepção individual e coletiva sobre o que é a didática e o seu objeto de estudo. Notou-se que os alunos compreendiam-na como uma disciplina que iria instruí-los sobre métodos apenas para instrumentalizar a aula. Entretanto, a experiência com a disciplina permitiu a compreensão do processo de ensino-aprendizagem como objeto de estudo dessa ciência, os paradigmas, as linhas de pensamentos e a necessidade da didática na prática educativa.

As vivências com a disciplina possibilitaram a compreensão da didática para além de métodos das disciplinas. Pôde-se entendê-la como a síntese de fatores técnicos, humanos, políticos e sociais nos quais o pedagógico insere-se, fornecendo subsídios para a prática educativa mais pedagógica e que considere a multidimensionalidade do processo educativo. Afinal, sabe-se que, para repensar a formação dos docentes, é preciso considerar seus saberes, o contexto social do seu local de trabalho e a estreita vinculação entre o ensino e a prática social ${ }^{(20-21)}$.

A formação e a prática educativa em saúde exige diálogo com as práticas pedagógicas ${ }^{(21)}$. Entretanto, a maior parte das universidades públicas e privadas, em seus cursos de pós-graduação, não ofertam disciplinas com ênfase na formação pedagógica e didática, culminando na formação de profissionais sem o conhecimento mínimo de teoria da educação (pedagogia) e teoria do ensino (didática) para orientar a prática docente ${ }^{(22-24)}$.

Dessa forma, torna-se necessária uma mobilização coletiva para a instituição da formação didático-pedagógica no stricto sensu, uma vez que esse espaço possibilita ascensão na docência, no ensino superior, e deve ser utilizado para conscientizar professores em formação sobre a qualidade e efetividade do processo de ensino-aprendizagem ${ }^{(25)}$. Além disso, a educação contínua ou permanente e o atendimento das circunstâncias do contexto socio-histórico e cultural, por exemplo a utilização de novas 
tecnologias no ensino presencial ou a distância (smartphone, notebook, plataformas virtuais de ensino, entre outros), têm sido cada vez mais utilizados nos diferentes contextos das práticas educativas. Decerto que os desafios existem para articular a dimensão pedagógica às ferramentas tecnológicas adequadas nas práticas educativas de saúde, na docência no ensino superior, assim como em outras modalidades ${ }^{(21-24)}$.

A didática instrumental restrita ao "como fazer pedagógico" como unidimensional precisa ser superada. É necessária a construção e consolidação de uma didática fundamental, que compreenda a multidimensionalidade no processo de ensino e aprendizagem e articule o "como fazer" ao "por que fazer" e "para que fazer", Além disso, essa didática fundamental ancora-se na relação entre teoria e prática como indissociáveis, ressaltando a importância de o aluno ter contato com diferentes formas de aproximação com o processo de aprendizagem ${ }^{(10)}$.

A compreensão da função do docente como mediador na produção do conhecimento e não como detentor absoluto do conhecimento também representa um desafio para os profissionais de saúde coletiva, no desenvolvimento da prática educativa em saúde. Ratifica-se a importância do profissional de saúde como educador, que deve priorizar a aplicabilidade da prática educativa como instrumento fundamental na assistência qualificada, incluindo o uso de estratégias e tecnologias adequadas para contribuir no processo de cuidado e estímulo ao empoderamento em saúde dos pacientes, familiares e comunidade, provendo saúde e prevenção de doenças e complicações ${ }^{(26)}$.

\section{Conclusão}

Os conhecimentos sobre o processo de ensino-aprendizagem produzidos nas aulas da disciplina Didática permitiram a ruptura da associação da disciplina com instrumentalização de técnicas de ensino apenas e a compreensão do processo pedagógico como multidimensional. Além disso, permitiu o aprendizado do contexto histórico, social e das tendências pedagógicas da didática, bem como possibilitou a compreensão da importância do planejamento das aulas para guiar a prática de ensino de maneira efetiva e a importância de vincular teoria e prática.

A Didática ainda representa desafio para os profissionais de saúde coletiva. A formação dos discentes dos cursos de pós-graduação stricto sensu em saúde coletiva requer, além dos conhecimentos específicos na área, o conhecimento da Didática para embasar a prática educativa de acordo com a pedagogia. Nesse panorama, a compreensão da Didática para além do "como fazer" pedagógico fornece subsídio para o desenvolvimento de práticas educativas com sentido, orientadas para a multidimensionalidade do processo educativo e constitui-se, portanto, componente curricular fundamental para a Pós-Graduação em Saúde Coletiva.

O contato e a aquisição de conhecimento de disciplinas pedagógicas, como a Didática, pelos profissionais da saúde são fundamentais durante a formação, sobretudo por ser a docência uma das áreas de atuação desses profissionais, além de possibilitar o desenvolvimento pessoal, acadêmico e profissional. Para a enfermagem, a atividade docente constitui-se em desafio, devido à ausência de disciplinas pedagógicas na maior parte das instituições de ensino superior. Dessa forma, ressalta-se a importância da introdução dessa disciplina na matriz curricular dos cursos de graduação e pós-graduação da área da saúde.

\section{Colaborações:}

1 - concepção, projeto, análise e interpretação dos dados: Hayla Nunes da Conceição, Mariana Rodrigues da Rocha, Haylla Simone Almeida Pacheco, Hilda Maria Martins Bandeira e Maria do Socorro Leal Lopes;

2 - redação do artigo e revisão crítica relevante do conteúdo intelectual: Hayla Nunes da Conceição, Mariana Rodrigues da Rocha, Haylla Simone Almeida Pacheco, Sara Ferreira Coelho, Hilda Maria Martins Bandeira e Maria do Socorro Leal Lopes; 
3 - aprovação final da versão a ser publicada: Hayla Nunes da Conceição, Mariana Rodrigues da Rocha, Haylla Simone Almeida Pacheco, Sara Ferreira Coelho, Hilda Maria Martins Bandeira e Maria do Socorro Leal Lopes.

\section{Referências}

1. Tomaz APKA, Tocantins FR, Souza SR. Estágio docência realizado num hospital universitário do estado do Rio de Janeiro - relato de experiência. $\mathrm{J}$ res: fundam care. $2014 \mathrm{abr} / \mathrm{jun}$;6(2):856-62. DOI: $10.9789 / 2175-5361.2014 \mathrm{v} 6 \mathrm{n} 2 \mathrm{p} 856$

2. Candau VM. A revisão da didática. In: Candau VM, organizador. Rumo a uma nova didática. 21a ed. Petrópolis: Vozes; 2011. p. 13-19.

3. Melo A, Urbanetz ST. Fundamentos de didática. Curitiba: IBPEX; 2008.

4. Freire P. Pedagogia da autonomia: saberes necessários à prática educativa. 34a ed. São Paulo: Paz e Terra; 1996.

5. Chamlian HC. Docência na universidade: professores inovadores na USP. Cad Pesqui. 2003 mar;(118):41-64. DOI: https://doi.org/10.1590/ S0100-15742003000100003

6. Brasil. Ministério da Saúde. Relatório da VIII Conferência Nacional de Saúde [Internet]. Brasília; 1986 [cited 2020 May 20]. Available from: http:// conselho.saude.gov.br/biblioteca/Relatorios/ relatorio_8.pdf

7. Fonseca AF, Corbo MD'A. organizadores. O território e o processo saúde-doença [Internet]. Rio de Janeiro: Fiocruz; 2007. (Coleção Educação Profissional e Docência em Saúde: a formação e o trabalho do Agente Comunitário de Saúde). [cited 2020 May 20]. Available from: http://www. rets.epsjv.fiocruz.br/sites/default/files/arquivos/ biblioteca/volume_1_0.pdf

8. Fortuna CM, Matumoto S, Mishima SM, Rodríguez AMMM. Collective Health Nursing: desires and practices. Rev Bras Enferm. 2019;72(Suppl 1):336-40. DOI: https://doi. org/10.1590/0034-7167-2017-0632

9. Behrens MA. O paradigma emergente e a prática pedagógica. 4a ed. Petrópolis, RJ: Vozes; 2010.

10. Candau VM. A didática na formação de educadores - da exaltação à negação: a busca da relevância. In: Candau VM, organizador. A didática em questão. 36a ed. Petrópolis, RJ: Vozes; 2014. p. 13-23.
11. Masetto MT. Planejamento da disciplina e da aula como espaços e tempos de aprendizagem e de formação profissional. In: Masetto MT. Desafios para a docência universitária na contemporanidade: professor e aluno em inter-ação adulta. São Paulo: Avercamp; 2015. p. 77-88.

12. Borges TS, Alencar G. Metodologias ativas na promoção da formação crítica do estudante: o uso das metodologias ativas como recurso didático na formação crítica do estudante do ensino superior. Cairu Rev [Internet]. 2014 [cited 2019 Oct 28];3(4):119-43. Available from: https://www.ea2.unicamp.br/mdocs-posts/ metodologias-ativas-na-promocao-da-formacaocritica-do-estudante-o-uso-das-metodologiasativas-como-recurso-didatico-na-formacao-criticado-estudante-do-ensino-superior/

13. Coelho MMF, Miranda KCL. Educação para emancipação dos sujeitos: reflexões sobre a prática educativa de enfermeiros. Rev Enferm Cent O Min. 2015;5(2):1714-21. DOI: https://doi. org/10.19175/recom.v0i0.499

14. Christensen CM, Horn MB, Staker H. Ensino híbrido: uma inovação disruptiva? uma introdução à teoria dos híbridos. Boston: Clayton Christensen Institute; 2013.

15. Roman C, Ellwanger J, Becker GC, Silveira AD, Machado CLB, Manfroi WC. Metodologias ativas de ensino-aprendizagem no processo de ensino em saúde no Brasil: uma revisão narrativa. Clin Biomed Res. 2017;37(4):349-57. DOI: http://dx.doi. org/10.4322/2357-9730.73911

16. Libâneo JC. Didática. 21a ed. São Paulo: Cortez; 1994.

17. Leadebal ODCP, Fontes WD, Nóbrega MML, Brito Filho GT. Análise das bases didático-pedagógicas para o ensino da sistematização da assistência enfermagem. Rev Min Enferm [Internet]. 2009 [cited 2020 May 20];13(1):57-64. Available From: https://cdn. publisher.gn1.link/reme.org.br/pdf/v13n1a10.pdf

18. Fusari JC. O planejamento do trabalho pedagógico: algumas indagações e tentativas de respostas [Internet]. Idéias [cited 2020 May 15];1990:(8):44-53. Available from: https://docplayer.com.br/16365924Jose-cerchi-fusari-o-planejamento-do-trabalhopedagogico-algumas-indagacoes-e-tentativas-derespostas.html

19. Carvalho SS, Costa JSP, Vilas Boas LBS, Nascimento Sobrinho CL. O papel do tirocínio 
docência na formação inicial do mestre em saúde coletiva: um relato de experiência. Rev Saúde. Com. 2018;14(1):1138-44. DOI 10.22481/rsc.v14i3.555

20. Tardif M, Lessard C. O trabalho docente: elementos para uma teoria da docência como profissão de interações humanas. 6a ed. Petrópolis (RJ): Vozes; 2011.

21. Oliveira WS. Didática em docência do ensino superior: (in)sucesso do ensino-aprendizagem na interação professor-aluno. Rev Cient Multidisc Núcleo Conhec. 2020;3(4):27-40. DOI: 10.32749/ nucleodoconhecimento.com.br/educacao/ didatica-em-docenciav

22. Silva VOD, Pinto ICDM. Produção científica sobre docência em saúde no Brasil. Saúde Debate. 2019;43(1):134-47. DOI: https://doi. org/10.1590/0103-11042019s112

23. Cruz GB. Didática e docência no ensino superior. Rev Bras Est Pedagog. 2017;98(250):672-89. DOI: https://doi.org/10.24109/2176-6681.rbep. $98 i 250.2931$

24. Figueiredo GA. A aplicação da didática e dos saberes pedagógicos ao ensino superior. Rev Pesq Educ Jur. 2018;4(2):18-34. DOI: http://dx.doi.org/10.26668/IndexLawJournals/ 2525-9636/2018.v4i2.4792

25. Zamprogna KM, Backes VMS, Menegaz JDC, Fraga FMR, Tristão FR, Silva GTR. Formação para a docência universitária: tendência dos Programas de Pós-Graduação em Enfermagem no Brasil. Rev Enferm UFSM. 2020;10(45):1-18. DOI: $10.5902 / 2179769239963$

26. Moreira TMM, Pinheiro JAM, Florêncio RS, Cestari VRF. Tecnologias para a promoção e o cuidado em saúde. Fortaleza: EdUECE; 2018.

Recebido: 6 de julho de 2020 Aprovado: 13 de agosto de 2020 Publicado: 24 de novembro de 2020

A Revista Baiana de Enfermagem utiliza a Licença Creative Commons - Atribuição-NãoComercial 4.0 Internacional. https://creativecommons.org/licenses/by-nc/4.0/ Este artigo é de acesso aberto distribuído sob os termos da Licença Creative Commons (CC BY-NC). Esta licença permite que outros remixem, adaptem e criem a partir do seu trabalho para fins não comerciais. Embora os novos trabalhos tenham de lhe atribuir o devido crédito e não possam ser usados para fins comerciais, os usuários não têm de licenciar esses trabalhos derivados sob os mesmos termos. 